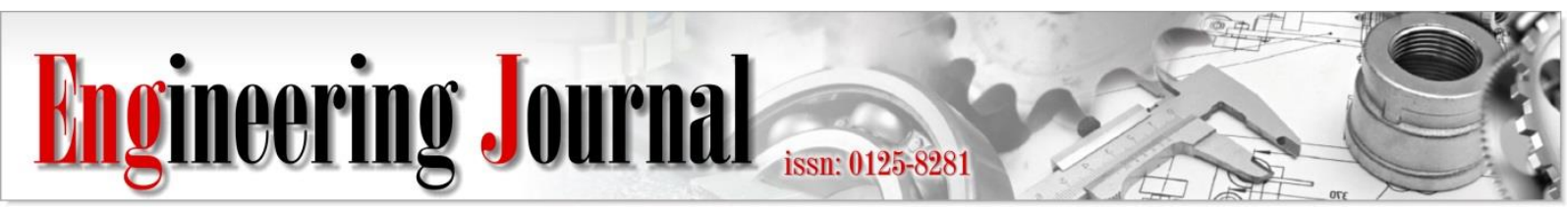

Article

\title{
Monitoring of Hot Corrosion Behaviors for Alloys and Aluminide Coatings under Molten Sulfate Film with Thermal Cycles
}

\author{
Seisho Take*, Misaki Kikuchi, Taro Atsumi, Taiga Ogura, Ryutaro Takenaka, \\ Haruki Koya, and Fuga Kinbara \\ National Institute of Technology, Oyama College, 771Nakakuki, Oyama City, Tochigi, 323-0806 Japan \\ *E-mail: wuc@oyama-ct.ac.jp (Corresponding author)
}

\begin{abstract}
In this study, a thin molten sulfate film was formed on the metallic samples and their corrosion processes have been monitored by electrochemical impedance technique under thermal cyclic condition. Inconel 600, nickel and aluminide diffusion coatings were used as samples. $50 \mathrm{~mol} \% \mathrm{Na}_{2} \mathrm{SO}_{4^{-}} 50 \mathrm{~mol} \% \mathrm{Li}_{2} \mathrm{SO}_{4}$ was used for preparing the molten sulfate film. Two kinds of specially designed electrochemical cells have been used in this study. One is three-electrode configuration and another is two-electrode configuration. Electrochemical impedance measurements were used for monitoring the degradation processes for all samples tested. It was found that both corrosion resistance and the change of molten sulfate film have been monitored successfully during 6 thermal cycles. In every thermal cycle, the corrosion resistance increased when the temperature shifted to lower values and decreased with the rising of temperature. Also, A drastic increase in corrosion resistance and the resistance of the molten salt film was observed when the temperature decreased below the melting point of the mixed molten sulfate film. Although both threeelectrode and two-electrode configurations were usable for electrochemical measurements under molten sulfate film, it was concluded that the newly designed two-electrode configuration is more suitable under thermal cyclic condition.
\end{abstract}

Keywords: Hot corrosion, electrochemistry, impedance, molten sulfate film, thermal cycle.

ENGINEERING JOURNAL Volume 23 Issue 4

Received 3 May 2019

Accepted 10 June 2019

Published 8 August 2019

Online at http://www.engj.org/

DOI:10.4186/ej.2019.23.4.193 


\section{Introduction}

Hot corrosion occurs on the metallic components of jet engines, gas turbines, boilers and waste burning furnaces [1,2]. It is a kind of accelerated corrosion caused by the existence of molten salt on the surface of metallic materials. Recently, materials used for certain components of new type nuclear reactor (Molten Salt Reactor, MSR) and electrode materials for Molten Carbonate Fuel Cell (MCFC) also encounter accelerated corrosion caused by molten salts [3, 4]. Since molten salt is electrolyte, the mechanism of hot corrosion is considered to be an electrochemical process. Therefore, electrochemical methods such as potential dynamic polarization (Tafel extrapolation), open potential measurement and electrochemical impedance measurement have been used by researchers to study hot corrosion or to evaluate hot corrosion resistance of materials [510]. However, most of the studies have been conducted in bulk molten salt which is not the exact situation encountered in real environments. Hot corrosion happens when a molten salt thin film forms on the surface of metallic component. There are many different aspects between bulk molten salt and thin molten salt film such as the diffusion rates of environmental gases to the surface of metallic components, the changes in chemical composition of molten salt film or even the decomposition of molten salt due to the rapid changes of gas pressure. Also, corrosion products can be carried away from the corrosion spots in the case of bulk molten salt by convection or diffusion and it may have effect on the sequential degradation process of metallic materials. Consequently, it is questionable for conducting studies of hot corrosion with electrochemical methods in bulk molten salt. On the other hand, not all electrochemical methods are suitable for studying hot corrosion mechanism especially for monitoring hot corrosion process. It is well known that electrochemical impedance technique is very useful for monitoring corrosion process and for understanding the characteristics of interfaces between metals and electrolytes. Compared to other electrochemical techniques, one of its advantages is that by applying a small amplitude of AC signal, it gives almost no damage to the tested corrosion process and thus long-term monitoring of corrosion process can be achieved. Electrochemical impedance technique has been widely used for different type of corrosion in aqueous solutions [11-13]. However, due to some difficulties for setting up electrochemical cell suitable for measurements under molten salt conditions at high temperature, application of electrochemical impedance to study of hot corrosion especially under molten salt film conditions has been rarely reported.

The corrosion of heat resistant alloys and protective aluminide coatings under molten salt film condition has been carried out in our lab with electrochemical techniques such as measuring changes in corrosion potential $\left(\mathrm{E}_{\mathrm{corr}}\right)$, Tafel extrapolation from polarization curves and electrochemical impedance [14-21]. In our previous researches, corrosion behavior and corrosion rates of alloys were investigated by potentiodynamic polarization under molten sulfate film condition. It was found that the oxygen partial pressure had a significant effect on polarization behavior of alloys under molten sulfate film condition. Corrosion rates of alloys changed greatly with the change in oxygen partial pressure. We also applied electrochemical impedance technique to the monitoring the impedance behaviors and corrosion resistance of alloys or protective coatings under molten salt film condition with an electrochemical cell designed especially for electrochemical measurements under molten salt condition [20]. Furthermore, in order to simulate the operating conditions for alloys and protective coatings more practically, the degradation processes of Inconel 600 and aluminide diffusion coatings were monitored by electrochemical impedance measurements under molten sulfate film with two thermal cycles [21]. In this study, up to 6 thermal cycles were applied for confirming the possibility and credibility of the electrochemical cell especially designed for measurements under molten salt film. Also, a new two-electrode configuration cell for electrochemical impedance monitoring was developed and applied to evaluating the degradation processes of metallic materials under molten sulfate film with thermal cycles.

\section{Experimental}

Inconel 600 alloy, pure nickel (99.9\%) and aluminide diffusion coatings on Inconel 600 (3 mm in width, 0.5 $\mathrm{mm}$ in thickness and $100 \mathrm{~mm}$ in length) were used in this study. The chemical composition of Inconel 600 is shown in Table 1. Aluminide diffusion coatings on Inconel 600 were prepared by pack cementation method. Inconel 600 was used as the substrate for aluminide diffusion coatings. After being polished by sanding paper to 2000 grit, it was cleaned with acetone in an ultrasonic bath. Then, it was put into a ceramic boat with a mixture powder of $\mathrm{Al}, \mathrm{Al}_{2} \mathrm{O}_{3}$ and $\mathrm{NH}_{4} \mathrm{Cl}\left(\mathrm{Al}_{2} \mathrm{O}_{3} 75 \mathrm{wt} \%, \quad \mathrm{Al} 20 \mathrm{wt} \%, \mathrm{NH}_{4} \mathrm{Cl} 5 \mathrm{wt} \%\right)$. The aluminide coating was obtained by heat treatment at $800^{\circ} \mathrm{C}$ for one hours under argon atmosphere. In order to fit the specially designed electrochemical cell, all samples used in this study were fabricated into an " $\mathrm{L}$ " shape [21]. 
Table 1. Chemical composition of Inconel 600.

\begin{tabular}{|c|c|c|c|c|}
\hline $\mathrm{Fe}$ & $\mathrm{Ni}$ & $\mathrm{Cr}$ & $\mathrm{Mn}$ & $\mathrm{C}$ \\
\hline $6-10$ & $>72$ & 15.7 & $<0.1$ & $<0.15$ \\
\hline
\end{tabular}

A mixture of $50 \mathrm{~mol}^{\%} \mathrm{Na}_{2} \mathrm{SO}_{4}-50 \mathrm{~mol}^{\%} \mathrm{Li}_{2} \mathrm{SO}_{4}$ was used as the molten sulfate resource for forming molten salt film. The melting point of the sulfate mixture was confirmed as $470^{\circ} \mathrm{C}$ by Differential Thermal Analysis (DTA) in our previous study [21]. Up to six thermal cycles were applied during the electrochemical impedance measurements. In order to monitor the behavior of both alloys and molten salt film itself, temperature range for thermal cycle was set from $450^{\circ} \mathrm{C}$ to $800^{\circ} \mathrm{C}\left(450^{\circ} \mathrm{C}\right.$ to $700^{\circ} \mathrm{C}$ for nickel). The raising and lowering rate for temperature were $3^{\circ} \mathrm{C} / \mathrm{min}$ and $1.6^{\circ} \mathrm{C} / \mathrm{min}$, respectively (Fig. 1).

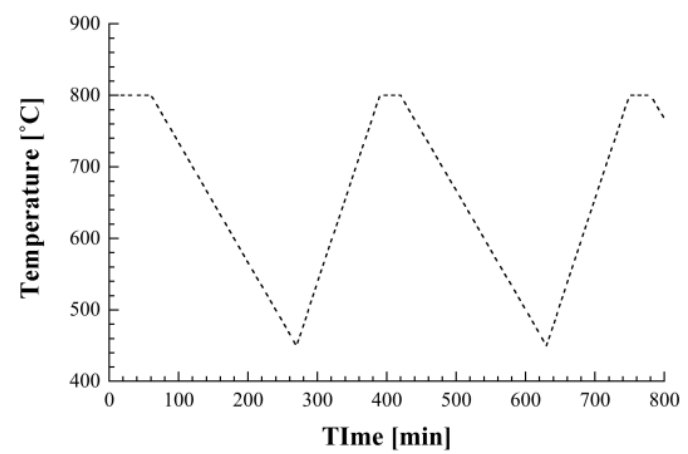

Fig. 1. Schematic diagram of thermal cycle. Temperature range: $450^{\circ} \mathrm{C} \sim 800^{\circ} \mathrm{C}$, raising rate: $3^{\circ} \mathrm{C} / \mathrm{min}$, lowering rate: $1.6^{\circ} \mathrm{C} / \mathrm{min}$, holding time at $800^{\circ} \mathrm{C}: 30 \mathrm{~min}(60 \mathrm{~min}$ for the first cycle).

The monitoring of hot corrosion processes of Inconel 600 and aluminide diffusion coating was conducted by electrochemical impedance measurement. Two types of electrochemical cell arrangement were designed especially for electrochemical impedance measurements under molten salts film. One is threeelectrode configuration. Figure 2 shows the schematic diagram of the specially designed three-electrode configuration cell. Reference electrode, which is $\mathrm{Ag} / \mathrm{Ag}^{-1}$ electrode sealed in a mullite tube, was installed on the surface of working electrode and the platinum wire was wrapped on the reference electrode as the counter electrode. Another type of electrochemical cell used in this study is two-electrode configuration. Two same samples were used in this configuration. One is served as working electrode, another is served as both counter electrode and reference electrode. For both cell configurations, before starting the measurements of electrochemical impedance, the crucible filled with molten sulfate was manually raised up in order to let the electrodes be immersed into molten sulfate for a few seconds. Then the crucible was lower down and a molten salt film was formed on the electrodes. Impedance measurements were conducted within a frequency range from $2 \times 10^{4} \mathrm{~Hz}$ to $10^{-1} \mathrm{~Hz}$. The amplitude of AC voltage applied is $10 \mathrm{mV}$.

\section{Results and Discussion}

Monitoring of degradation processes for alloys and aluminide protective coatings under molten sulfate film with 6 thermal cycles has been conducted with both three-electrode and two-electrode configuration electrochemical cells. Results obtained with three-electrode and two-electrode configuration cells will be discussed, respectively.

\subsection{Results with Three-electrode Configuration}

\subsubsection{Impedance behaviors of Inconel 600 and aluminide coatings}

Figure 3 shows the impedance behavior for Inconel 600 and its change with temperature under molten sulfate film at the second thermal cycle. It can be seen that the impedance within the tested frequency range increased with the decreasing of temperature. It was also found that impedance behaviour at $450^{\circ} \mathrm{C}$ differs greatly from those observed at higher temperature. At $450^{\circ} \mathrm{C}$, much higher impedance value at high frequency was 
observed. As reported before, the abrupt increase of impedance value is due to the solidification of molten sulfate film since its melting point was confirmed as $470^{\circ} \mathrm{C}$ [21]. Similar changes in impedance behavior with temperature were observed in every thermal cycle.

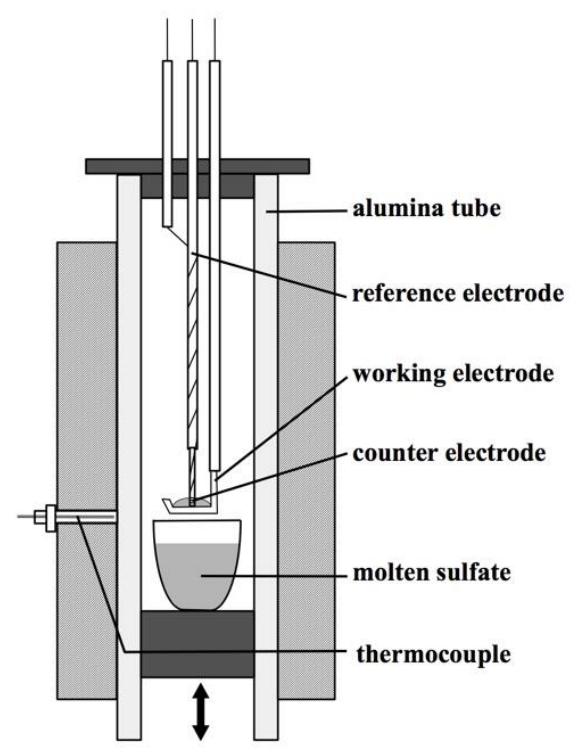

Fig. 2. Electrochemical cell designed for electrochemical measurements under molten salt film condition.

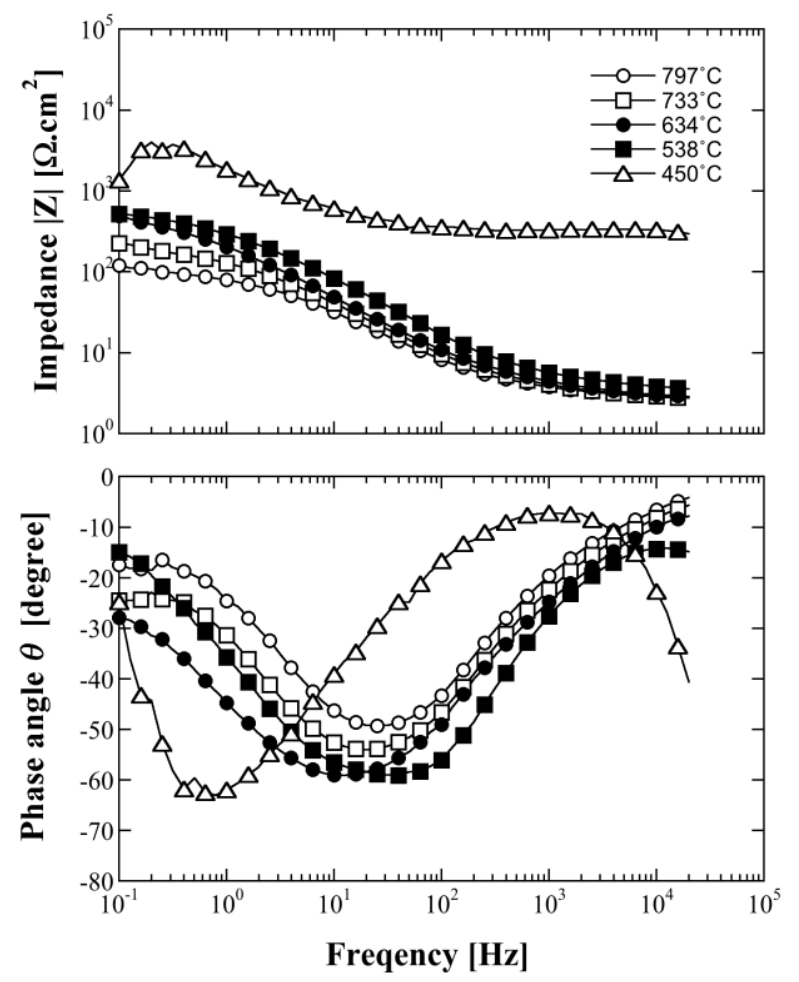

Fig. 3. Impedance behavior for Inconel 600 and its change with temperature under molten sulfate film during the second thermal cycle. The test was conducted with three-electrode configuration electrochemical cell.

The impedance behavior of aluminide diffusion coating on Inconel 600 and its change with temperature under molten salt film at second thermal cycle was shown in Fig. 4. Similar to Inconel 600, impedance increased with the decreasing of temperature and a large increase of impedance was observed when the 
temperature was lowered to $450^{\circ} \mathrm{C}$. However, different from Inconel 600 , a relatively large phase shift occurred at high frequency area. The impedance at high frequency area is also higher than that of Inconel 600 and increased with the temperature shifting to lower value. Our previous studies $[9,20]$ on aluminide coatings confirmed that the impedance component at high frequency area represents the characteristics of aluminum oxide formed on the surface of aluminide diffusion coating. The phase shift at high frequency is due to the capacitive properties of the aluminum oxide formed on the coating surface. The higher impedance value compared to that for Inconel 600 alloy at high frequency area represents not only the solution resistance $\mathrm{R}_{\mathrm{s}}$ but a total of $\mathrm{R}_{s}$ and the resistance of aluminum oxide film $\mathrm{R}_{\mathrm{f}}$. Therefore, in the case of aluminide diffusion coating, information about the electrochemical reaction (corrosion resistance $\mathrm{R}_{\mathrm{c}}$ ) and the aluminum oxide layer can be obtained at the same time by monitoring the changes in impedance at different frequency areas.

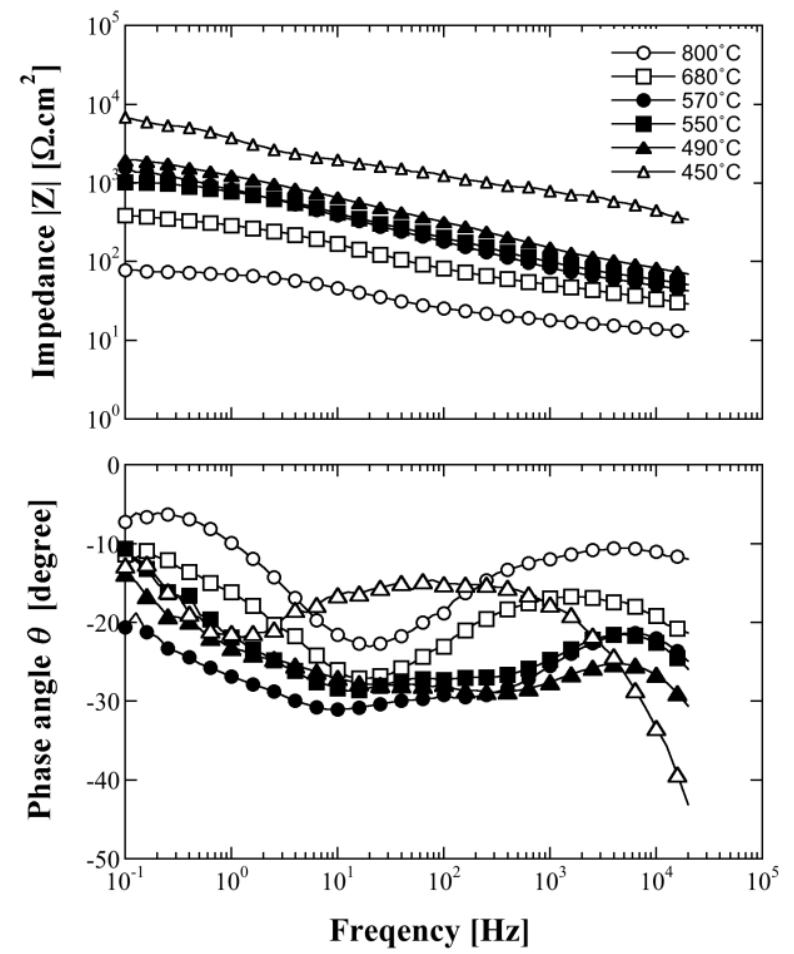

Fig. 4. Impedance behavior for aluminide diffusion coating on Inconel 600 and its change with temperature under molten sulfate film during the second thermal cycle. The test was conducted with three-electrode configuration electrochemical cell.

\subsubsection{Monitoring of corrosion processes for Inconel 600 and aluminide coatings}

In the case of Inconel 600, the impedance at low frequency represents the corrosion resistance $R_{c}$ and the impedance at high frequency represents the molten film solution resistance $\mathrm{R}_{\mathrm{s}}$ according to the results of Fig.3. Therefore, by monitoring the impedance changes at different frequency areas, information about the change of corrosion resistance (low frequency), solution resistance or the change about molten salt film itself (high frequency) can be obtained. Figure 5 shows the monitoring result of corrosion process for Inconel 600 during 6 thermal cycles under molten sulfate film. Every thermal cycle started from $800^{\circ} \mathrm{C}$. In every thermal cycle, corrosion resistance $\mathrm{R}_{\mathrm{c}}$ kept on increasing gradually with the dropping of temperature. There was an abrupt increase of the corrosion resistance $R_{c}$ when the temperature was lower than $470^{\circ} \mathrm{C}$. On the other hand, solution resistance $R_{s}$ remained almost constant within the temperature range from $800^{\circ} \mathrm{C}$ to $470^{\circ} \mathrm{C}$. However, when temperature shifted to a value lower than $470^{\circ} \mathrm{C}$, a big increase of $R_{s}$ was observed. When temperature started to increase, $R_{s}$ began to decrease greatly and became the same order of value finally as that before the abrupt increase. Same phenomenon occurred in every thermal cycle. As mentioned in the experimental, the melting point for the mixture of sulfate used in this study was confirmed to be $470^{\circ} \mathrm{C}$ by DTA. Therefore, the abrupt increase of $R_{s}$ is because the molten salt film changed from liquid state to solid state. The rapid increase of $R_{s}$ is also the reason for the big increase of corrosion resistance $R_{c}$ at the same 
temperature. Therefore, by checking both $\mathrm{R}_{\mathrm{c}} \& \mathrm{R}_{\mathrm{s}}$ at the same time, not only corrosion resistance but also the information about molten salt film itself can also be obtained, which is very helpful for a better understanding about the whole degradation process.

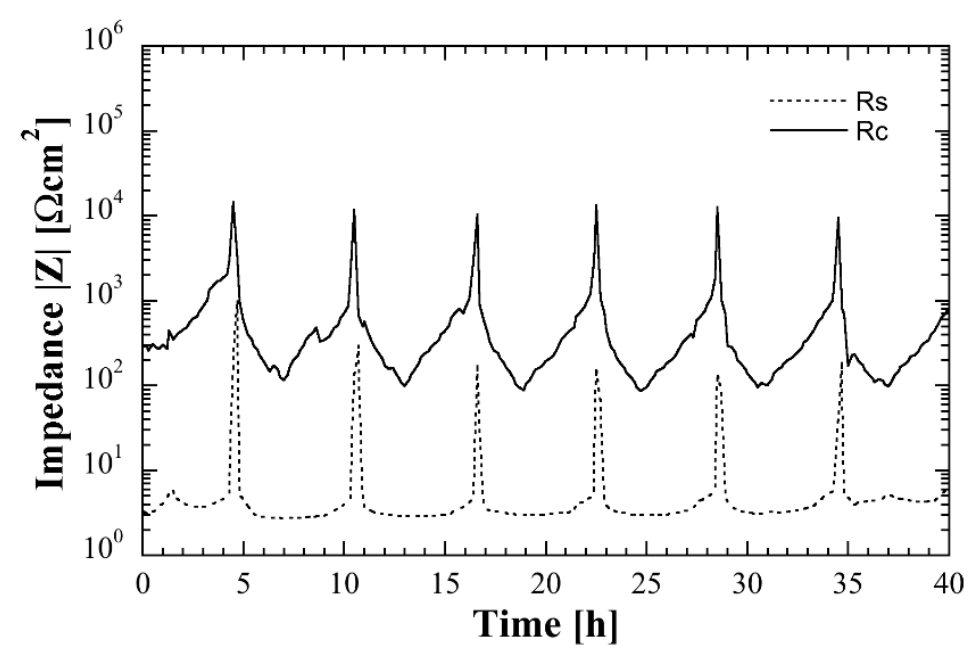

Fig. 5. Monitoring results for Inconel 600 during 6 thermal cycles under molten sulfate film with threeelectrode configuration cell. $\mathrm{R}_{\mathrm{c}}$ : corrosion resistance, $\mathrm{R}_{\mathrm{s}}$ : solution resistance of molten sulfate film.

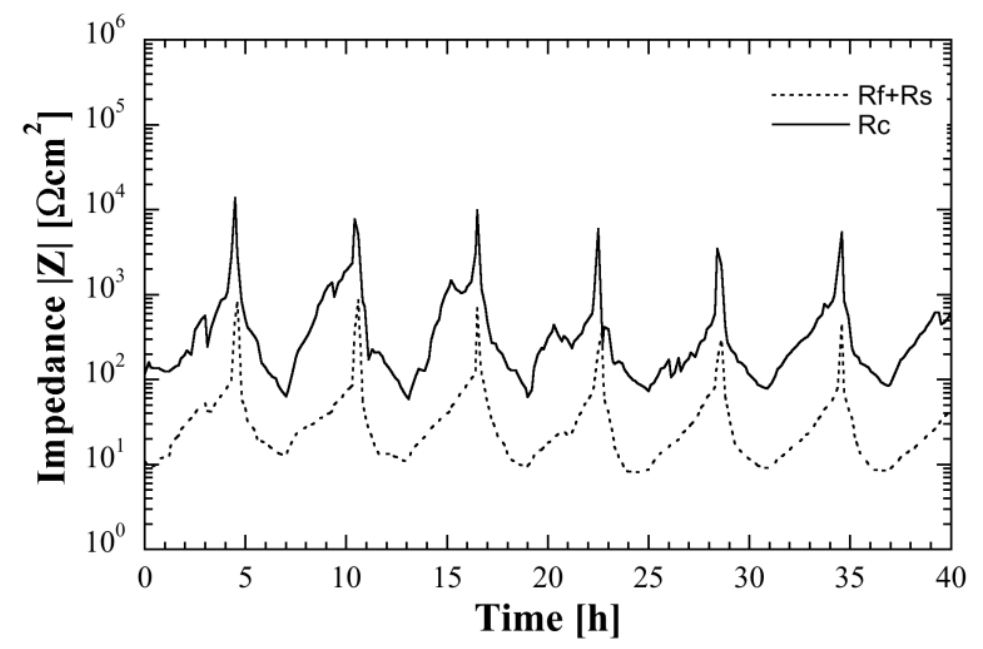

Fig. 6. Monitoring result for aluminide diffusion coating on Inconel 600 during 6 thermal cycles under molten sulfate film with three-electrode configuration cell. $\mathrm{R}_{\mathrm{c}}$ : corrosion resistance, $\mathrm{R}_{\mathrm{f}}$ : resistance of aluminum oxide layer, $\mathrm{R}_{\mathrm{s}}$ : solution resistance of molten sulfate film.

The monitoring result for aluminide diffusion coating on Inconel 600 during 6 thermal cycles under molten sulfate film is shown in Fig. 6. Similar to the result for Inconel 600 (Fig. 5), corrosion resistance $\mathrm{R}_{c}$ increased with the decreasing of temperature and decreased with the increasing of temperature in every thermal cycle. Since the impedance value at high frequency area represents a total amount of resistance from aluminum oxide film $R_{f}$ and solution resistance of molten salt $R_{s}$, mixed information was obtained from Fig. 6. During the temperature range from $800^{\circ} \mathrm{C}$ to $470^{\circ} \mathrm{C}$, the relative higher value of resistance compared to that of Inconel 600 (Fig. 5) is due to the resistance of aluminum oxide film formed on coating surface. When temperature was lowered below the melting point of the molten salt, the value of $R_{f}+R_{s}$ increased greatly, meaning the salt film changed from liquid to solid. It is also can be seen that $R_{f}+R_{s}$ did not remained constant as Inconel $600 \mathrm{did}$ (Fig. 5). It is considered that the change of impedance value with temperature at high frequency area $\left(\mathrm{R}_{\mathrm{f}}+\mathrm{R}_{\mathrm{s}}\right)$ is due to the changing of $\mathrm{R}_{\mathrm{f}}$ with temperature. Figure 7 shows the changes in corrosion resistance for Inconel 600 and aluminide diffusion coating with thermal cycle at $800^{\circ} \mathrm{C}$. For both Inconel 600 
and aluminide diffusion coating, corrosion resistance decreased slightly at first thermal cycle and then remained constant during the other 5 thermal cycles. From the above results, it is concluded that the degradation process for Inconel 600 and aluminide diffusion coating was successfully monitored and the specially designed three-electrode electrochemical cell by us is stable enough for evaluating hot corrosion process under molten salt film with up to 6 thermal cycles.

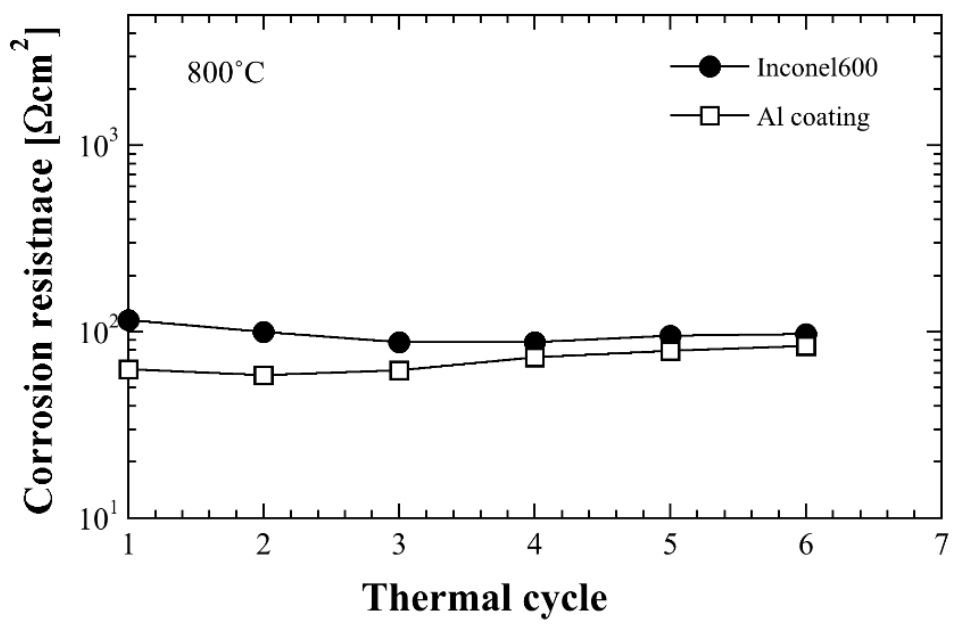

Fig. 7. Changes in corrosion resistance Rc at $800^{\circ} \mathrm{C}$ during 6 thermal cycles test for Inconel 600 and aluminide coating under molten sulfate film. The test was conducted with three-electrode configuration.

\subsection{Results with Two-electrode Configuration}

The electrochemical cell with three-electrode configuration which was designed by us has been played an important role for evaluating and monitoring the degradation processes of alloys and protective coatings under molten salt film conditions. It also showed the possibility and some credibility even under molten salt film with thermal cyclic conditions. However, it is difficult to use it under more aggressive thermal conditions because the weakness of ceramic tube used for reference electrode and the deformation of whole electrode setting due to the different thermal expansion that every electrode has. In order to improve the electrochemical cell to be more suitable for measurements under molten salt with more severe thermal cycles, two-electrode configuration electrochemical sell was designed and applied to monitoring the corrosion process of Inconel 600 and aluminide diffusion coating under molten sulfate film with 6 thermal cycles.

\subsubsection{Impedance behaviors of Inconel 600 and aluminide coatings}

Figure 8 and Figure 9 show the impedance behaviors and their changes for Inconel 600 and aluminide diffusion coating under molten sulfate film at second thermal cycle, respectively. It can be seen that similar results were obtained compared to those obtained with three-electrode configuration. It means that under molten sulfate film with thermal cycle, two-electrode configuration is applicable to electrochemical impedance measurement and can give the same correct information about impedance behavior as threeelectrode configuration did. 


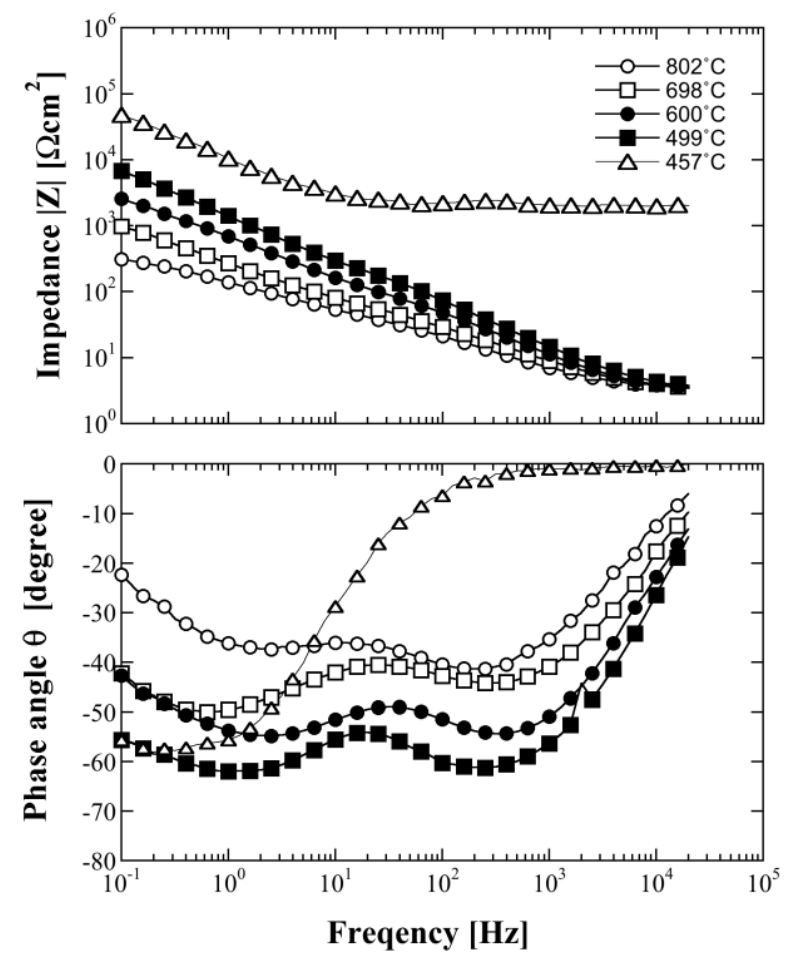

Fig. 8. Impedance behavior for Inconel 600 and its change with temperature under molten sulfate film during the second thermal cycle. The test was conducted with two-electrode configuration electrochemical cell.
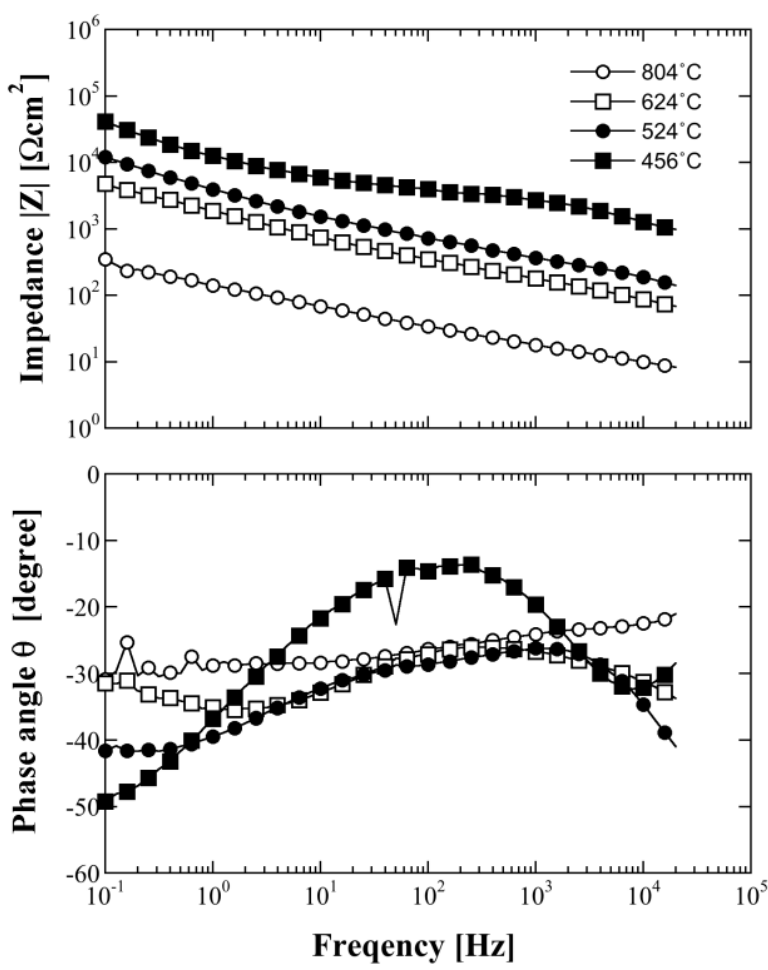

Fig. 9. Impedance behavior for aluminide diffusion coating on Inconel 600 and its change with temperature under molten sulfate film during the second thermal cycle. The test was conducted with twoelectrode configuration electrochemical cell. 


\subsubsection{Monitoring of corrosion processes for Inconel 600 and aluminide coatings}

Figure 10 and Figure 11 show the monitoring results for Inconel 600 and aluminide diffusion coating, respectively. During 6 thermal cycles, the monitoring results with two-electrode configuration correlated well with the results obtained by using three-electrode configuration (Fig. 5, Fig. 6), indicating two-electrode configuration electrochemical cell is qualified for electrochemical impedance tests under molten sulfate film with thermal cycles. In the case of Inconel 600, it can be seen that solution resistance of molten sulfate film kept in a more constant temperature-independent value compared to that obtained with three-electrode configuration when the molten sulfate film was in a liquid state (above $470^{\circ} \mathrm{C}$ ). It is considered that this difference for $R_{s}$ changing is due the difference of geometric shape between three-electrode configuration and two-electrode configuration. The later has a more uniform molten sulfate film layer formed between electrodes and bigger contact area.

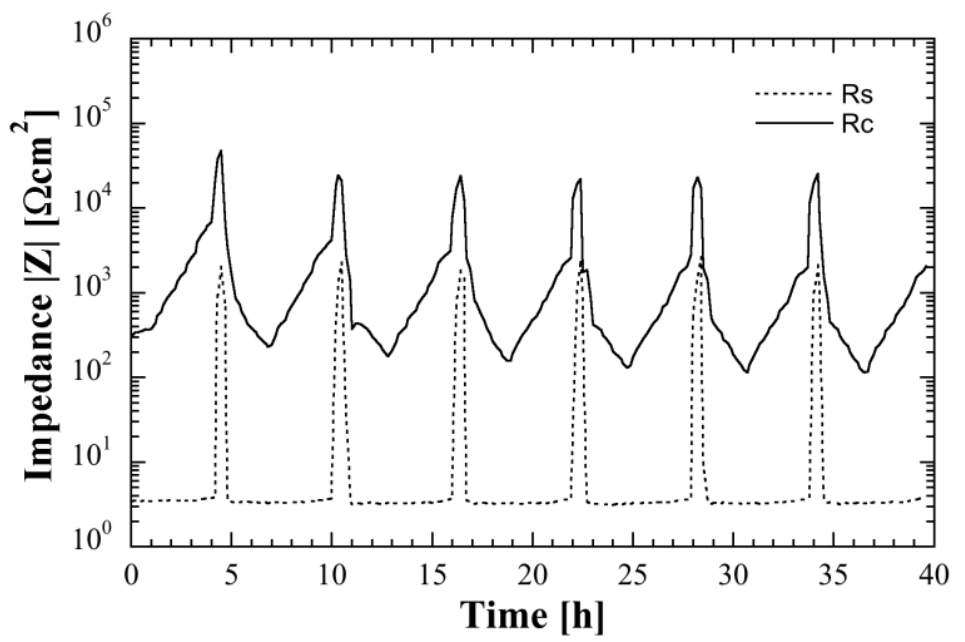

Fig. 10. Monitoring results for Inconel 600 during 6 thermal cycles under molten sulfate film with twoelectrode configuration cell. $\mathrm{R}_{\mathrm{c}}$ : corrosion resistance, $\mathrm{R}_{\mathrm{s}}$ : solution resistance of molten sulfate film.

For aluminide diffusion coating (Fig. 11), corrosion resistance $\mathrm{R}_{\mathrm{c}}$ and the state of surface aluminum oxide layer $\mathrm{R}_{\mathrm{f}}$ did not change regularly with temperature in first thermal cycle. The reason for it is considered due to the formation and some local crackdown of aluminum oxide layer during the initial stage of electrochemical impedance measurement. With the aluminum oxide layer become stable, the irregular change of impedance disappeared after first thermal cycle.

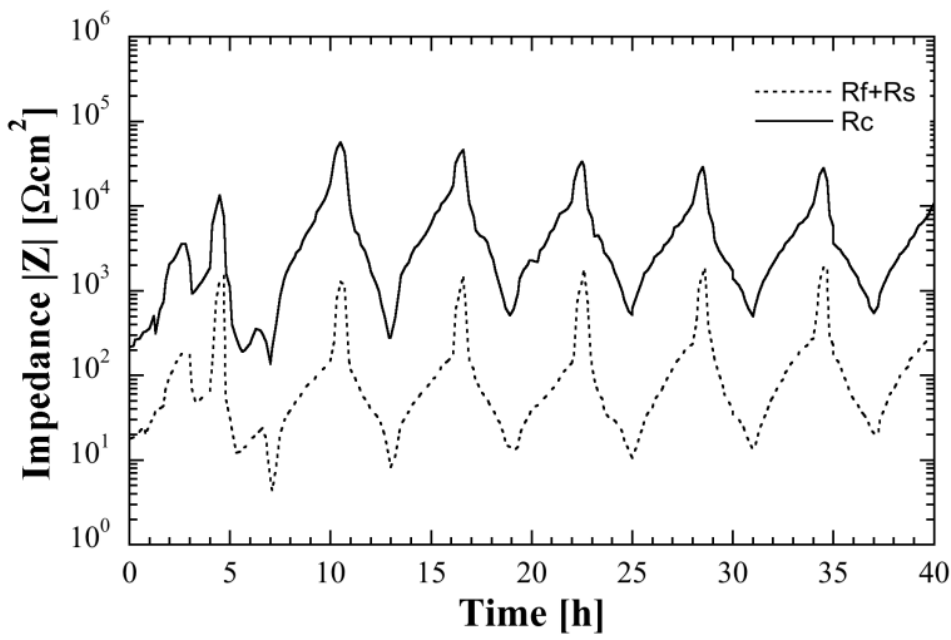

Fig. 11. Monitoring result for aluminide diffusion coating on Inconel 600 during 6 thermal cycles under molten sulfate film with two-electrode configuration cell. $\mathrm{R}_{\mathrm{c}}$ : corrosion resistance, $\mathrm{R}_{\mathrm{f}}$. resistance of aluminum oxide layer, $\mathrm{R}_{\mathrm{s}}$ : solution resistance of molten sulfate film. 


\subsection{Monitoring Results for Nickel with Two-electrode Configuration}

Another advantage for two-electrode configuration electrochemical cell is that it is suitable for more materials with different corrosion resistance and mechanical properties. One typical material for proving this advantage is nickel. The mechanical property of nickel is not very good at high temperature. Recrystallization and the increasing of grain size at temperature over $700^{\circ} \mathrm{C}$ can lower the strength of nickel. The corrosion resistance of nickel in molten sulfate is also not good because the eutectic mixture of nickel and nickel sulfide has a melting point lower than $800^{\circ} \mathrm{C}$. In the case of three-electrode configuration electrochemical cell designed by us, it needs the working sample strong enough to handle the tension between reference electrode and working sample (Fig. 2) in order to let reference electrode and working electrode get contacted to each other. Therefore, the monitoring of degradation process of nickel under molten sulfate film with thermal cycles was conducted for the first time by using two-electrode configuration electrochemical cell which is thought to be able to solve the above problem. The upper limit temperature for thermal cycle is changed from $800^{\circ} \mathrm{C}$ to $700^{\circ} \mathrm{C}$ for getting better and stable information from electrochemical impedance measurements.

Figure 12 shows impedance behavior and its changes with temperature for nickel under molten sulfate film at second thermal cycle. Compared to the result for Inconel 600, similar single time constant impedance behavior was observed but the impedance value was lower than that of Inconel 600 at same temperature. Monitoring results under 6 thermal cycles is shown in Fig. 13. It can be seen that in every thermal cycle, corrosion resistance $\mathrm{R}_{\mathrm{c}}$ changed with the changing of temperature while solution resistance did not change greatly with temperature when it is above $470^{\circ} \mathrm{C}$. After 6 thermal cycles, it was found by surface observation that nickel oxide layer was formed on the surface but no obvious corrosion or nickel sulfide was confirmed. The changes of corrosion resistance $R_{c}$ for Inconel 600 , aluminide diffusion coating and nickel at $700^{\circ} \mathrm{C}$ during 6 thermal cycle under molten sulfate film are shown in Fig. 14. Compared to nickel, aluminide diffusion coating and Inconel 600 showed relatively higher corrosion resistance, which is well correlated with the previous reports. From the above results, it is concluded that two-electrode configuration is more applicable and suitable for monitoring the degradation process of metallic materials under molten sulfate film with thermal cycles.

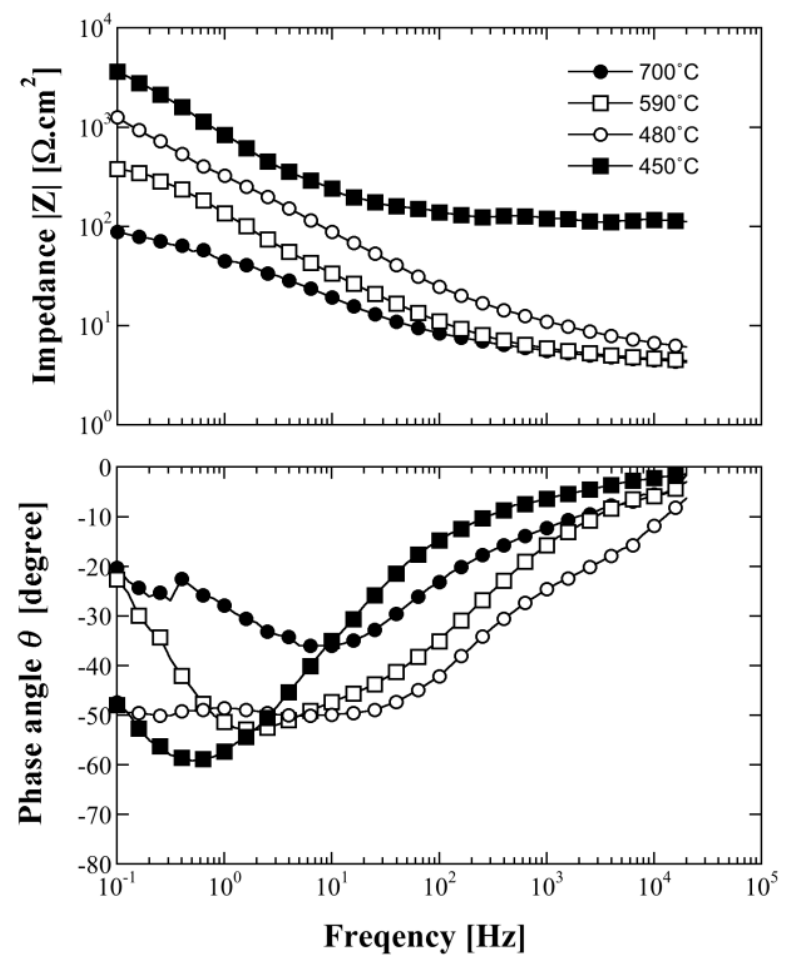

Fig. 12. Impedance behavior for nickel and its change with temperature under molten sulfate film during the second thermal cycle. The test was conducted with two-electrode configuration electrochemical cell. 


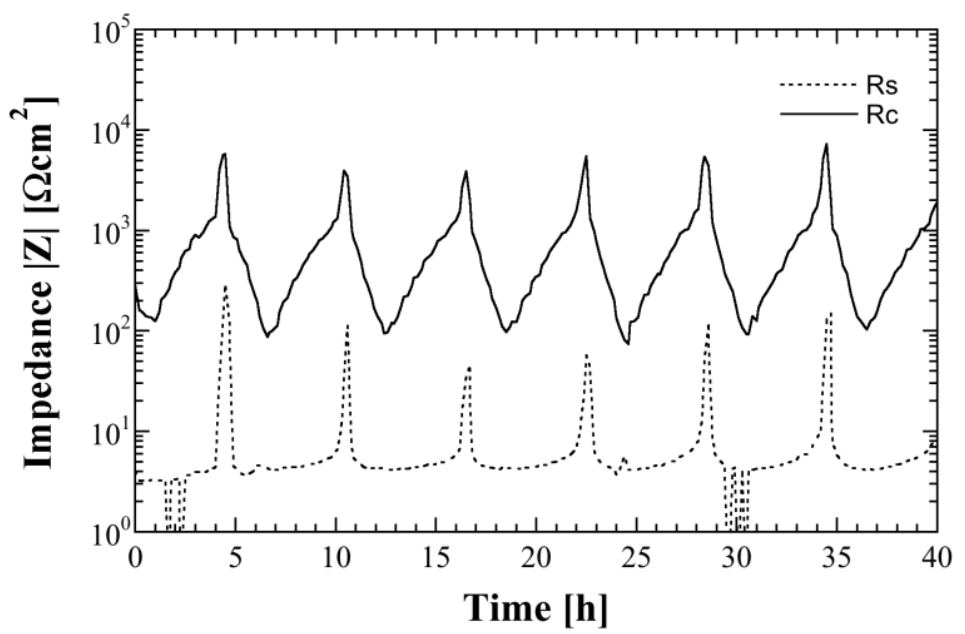

Fig. 13. Monitoring results for Inconel 600 during 6 thermal cycles under molten sulfate film with twoelectrode configuration cell. $\mathrm{R}_{c}$ : corrosion resistance, $\mathrm{R}_{\mathrm{s}}$ : solution resistance of molten sulfate film.

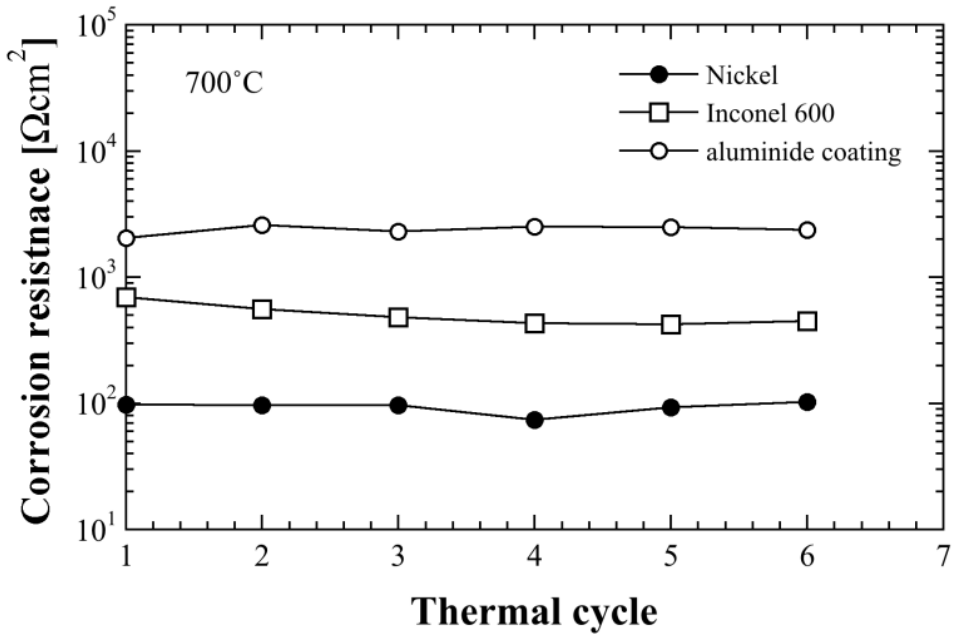

Fig. 14. Changes in corrosion resistance Rc at $700^{\circ} \mathrm{C}$ during 6 thermal cycles test for nickel, Inconel 600 and aluminide coating under molten sulfate film. The test was conducted with two-electrode configuration.

\section{Conclusions}

With specially designed electrochemical cells, the corrosion processes of Inconel 600, nickel and aluminide coatings under molten sulfate film with up to 6 thermal cycles have been successfully monitored. Both Inconel600 and aluminide coatings showed excellent and stable corrosion resistance under molten sulfate film with 6 thermal cycles. For aluminide coatings, information about surface aluminum oxide film was obtained from the impedance at high frequency area. Information about molten sulfate film was also monitored. Two-electrode configuration electrochemical cell was found to be applicable and the obtained information reflected the corrosion process same as three-electrode configuration. Two-electrode configuration is considered to be more suitable and promising for monitoring corrosion process under molten salt film with more aggressive thermal cycling conditions.

\section{References}

[1] J. Stringer, "Hot corrosion of high-temperature alloys," Annual Review of Materials Science, vol. 7, pp. 477509, Aug. 1977. 
[2] F. J. Wall and S. T. Michael, "Hot corrosion problems associated with gas turbines," ASTM Special Technical Publication STO, no. 422, pp. 223-245, 1967.

[3] P. Slama and M. Marecek, "Corrosion testing of nickel alloy for molten salt reactors," J. Achievement in Materials and Manufacture Engineering, vol. 39, no. 2, pp. 78-85, Jun. 2015.

[4] S. Frangini, "Corrosion of structural materials in molten carbonate fuel cells: An overview," Molten Salt Forum, vol. 7, pp. 135-154, 2003.

[5] D. A. Shores, "Use of anodic polarization in fused $\mathrm{Na}_{2} \mathrm{SO}_{4}$ for estimating hot corrosion rates," Corrosion, vol. 31, no. 12, pp. 434-440, 1975.

[6] A. Rahmel, "Electrochemical aspects of molten-salt-enhanced corrosion," Mater. Sci. and Eng., vol. 87, pp. 345-352, Mar. 1987.

[7] R. A. Rapp, "Chemistry and electrochemistry of the hot corrosion of metals," Corrosion, vol. 42, no. 10, pp. 568-577, 1986.

[8] C. Wu, A. Nishikata, T. Tsuru, and A. Takei, "Evaluation of high temperature corrosion resistance of Al diffusion coatings by AC impedance method," J. Japan Inst. Metals, vol. 56, no. 10, pp. 1161-1167, 1992.

[9] C. Wu, A. Nishikata, T. Tsuru, and A. Takei, "Evaluation of high temperature corrosion resistance of $\mathrm{Al}$ diffusion coatings under heat cycle conditions using AC impedance method," J. Japan Inst. Metals, vol. 57, no. 2, pp. 170-175, 1993.

[10] C. Wu and M Okuyama, "Evaluation of high temperature corrosion resistance of Al plasma spray coatings in molten sulfates at $1073 \mathrm{~K}$ by electrochemical measurements," Materials Transactions, JIM, vol. 37, no. 5, pp. 991-997, 1996.

[11] F. Mansfeld, "Use of electrochemical impedance spectroscopy for the study of corrosion protection by polymer coatings," J. Applied Electrochemistry, vol. 25, no. 3, pp. 187-202, Mar. 1995.

[12] A. Nishikata, Y. Ichihara, and T. Tsuru, "An application of electrochemical impedance spectroscopy to atmospheric corrosion study," Corrosion Science, vol. 37, no. 6, pp. 897-911, Jun. 1995.

[13] S. Tamilselvi, V. Raman, and N. Rajendran, "Corrosion behaviour of Ti-6Al-7Nb and Ti-6Al-4V ELI alloys in the simulated body fluid solution by electrochemical impedance spectroscopy," Electrochimica Acta, vol. 52, no. 3, pp. 839-846, Nov. 2006.

[14] C. Wu and M. Okuyama, "Evaluation of high temperature corrosion resistance of Ni under molten sulfate film by electrochemical impedance method," in Proc. 44th Japan Conference on Materials and Environments, September, 1997, pp. 227-230.

[15] S. Take, S. Maruyama, M. Okuyama, D. B. Mitton, and R. Latanision, "Evaluation of hot corrosion resistance of alloys under molten sulfate films by electrochemical techniques," in Proc. 194th ECS, October, 1998, p. 294.

[16] S. Take, Y. Itoi, and M. Okuyama, "High temperature corrosion resistance of alloys under molten sulfate film," in Proc. 48th Japan Conference on Materials and Environments, September, 2001, pp. 441-444.

[17] S. Take, M. Hasegawa, and Y. Itoi, "High temperature corrosion resistance of Al diffusion coatings under molten sulfate film," in Proc. 73th Conference of the Electrochemical Society of Japan, April, 2006, p. 70.

[18] S. Take, M. Hasegawa, and Y. Itoi, "Evaluation of hot corrosion resistance of alloys and Al diffusion coatings under molten sulfate film by electrochemical techniques," in Proc. Of $3 r d$ International Symposium on Marine Corrosion and Control, June, 2006, pp. 80-84.

[19] S. Take, M. Hasegawa, and Y. Itoi, "Evaluation of hot corrosion resistance for Al diffusion coatings under molten sulfate film by AC impedance technique," in Proc. 53th Japan Conference on Materials and Environments, September, 2006, pp. 393-394.

[20] S. Take, Y. Suda, T. Shirai, M. Hasegawa, and Y. Itoi, "Monitoring of degradation process of alloys and $\mathrm{Al}$ diffusion coatings under molten sulfate film by electrochemical impedance measurements," ECS Transactions, vol. 16, no. 44, pp. 43-50, 2009.

[21] S. Take, S. Yoshinaga, M, Yanagita, and Y. Itoi, "Monitoring the degradation process of Inconel 600 and its aluminide coatings under molten sulfate film with thermal cycles by electrochemical measurements," Corrosion Science and Technology, vol. 15, no. 6, pp. 259-264, 2016. 